\title{
Elevated Interleukin-6 Concentration and Alterations of the Coagulation System Are Associated with the Development of Intraventricular Hemorrhage in Extremely Preterm Infants
}

\author{
Christine Poralla $^{a}$ Hans-Jörg Hertfelder ${ }^{b}$ Johannes Oldenburg ${ }^{b}$ \\ Andreas Müller ${ }^{a}$ Peter Bartmann ${ }^{a}$ Axel Heep ${ }^{a}$ \\ ${ }^{\mathrm{a}}$ Department of Neonatology and ${ }^{\mathrm{b}}$ Institute of Experimental Hematology and Transfusion Medicine, \\ University of Bonn, Bonn, Germany
}

\section{Key Words}

Extreme prematurity $\cdot$ Intraventricular hemorrhage •

Coagulation $\cdot$ Inflammation $\cdot$ Interleukin-6

\begin{abstract}
Background: Pathogenesis of intraventricular hemorrhage (IVH) in premature infants is multifactorial. Little is known about the influence of pro-inflammatory cytokine activation on the coagulation system in extremely preterm infants and its impact on the development of IVH. Objective: To determine the interaction between serum interleukin- 6 (IL-6) and the coagulation system in preterm infants predisposed to the development of IVH. Methods: Vitamin K-dependent coagulation factors were examined retrospectively in $132 \mathrm{ex}$ tremely preterm infants prior to vitamin $\mathrm{K}$ administration at the first day of life. Patients were grouped according to the occurrence of IVH and serum concentration of IL- $6>\mid<100$ $\mathrm{pg} / \mathrm{ml}$. Results: Occurrence of IVH was associated with clinical diagnosis of chorioamnionitis, low gestational age, high CRIB score, air leak, catecholamine treatment, low initial hematocrit and increased serum concentration of IL-6. Infants developing IVH showed a diminished coagulation profile.
\end{abstract}

Multivariable logistic regression analysis revealed decreased activity of coagulation factor VII, development of pneumothorax and low hematocrit as independent risk factors for the development of IVH. An increased IL- 6 serum concentration was associated with a significantly decreased activity of coagulation factor VII and increased levels of fibrinogen. Conclusions: The association of elevated IL- 6 levels with alterations of the coagulation profile and development of IVH found in our study supports the assumption of a close pathophysiological relation between inflammation and IVH.

Copyright $\odot 2012$ S. Karger AG, Basel

\section{Introduction}

Development of intraventricular hemorrhage (IVH) is a serious complication following preterm birth. In particular, extremely preterm infants born with a gestational age less than 28 weeks are susceptible to IVH, which occurs in $20-25 \%$ of them and is strongly associated with neurodevelopmental deficits and long-term disabilities in the surviving infants [1-3].

\section{KARGER}

Fax +4161306 1234 E-Mail karger@karger.ch www.karger.com
(C) 2012 S. Karger AG, Base

$1661-7800 / 12 / 1024-0270 \$ 38.00 / 0$

Accessible online at:

www.karger.com/neo
Dr. Christine Poralla

Department of Neonatology, University of Bonn

Adenauerallee 119

DE-53113 Bonn (Germany)

Tel.+49228287 16574, E-Mail christine.poralla@ukb.uni-bonn.de 
Increased levels of interleukin-6 (IL-6) in cord blood and in the serum of preterm infants and their mothers, respectively, have been shown to be associated with the development of IVH in preterm infants [4-6].

To date, clinical data confirming an interaction between systemic inflammation and the coagulation profile with respect to the development of IVH in extremely preterm infants are scarce. Coagulation proteins are synthesized in early fetal life independently from the maternal hemostatic system, as these proteins do not cross the placental barrier [7]. Plasma concentrations of coagulation proteins change depending on gestational age [8-10]. Reference values of the coagulation system of full-term infants and preterm infants with a gestational age of 30-36 weeks at birth are available $[8,9]$. Data describing the coagulation system of preterm infants born with a gestational age less than 28 weeks are still rare. One may speculate that perinatal risk factors such as placental disorders or amnion infection syndrome may interfere with coagulation protein synthesis and/or consumption in these infants [11].

An activated systemic pro-inflammatory cytokine response is a common finding in perinatal infection leading to preterm delivery. Systemic inflammation results in activation of coagulation due to tissue factor-mediated thrombin generation, downregulation of physiological anticoagulant mechanisms, and inhibition of fibrinolysis. Pro-inflammatory cytokines such as TNF- $\alpha$ and IL- 6 enhance the expression of tissue factor. Tissue factor is a glycoprotein that is expressed on monocytes and endothelial cells upon stimulation with endotoxins. It forms a complex with activated coagulation factor VII which activates the coagulation cascade. Vice versa, activation of the coagulation system may substantially affect inflammatory responses by direct and indirect mechanisms $[12,13]$.

Aim of this study was to analyze the impact of increased serum levels of IL- 6 as marker of postnatal inflammation on the coagulation system and the risk of developing intraventricular hemorrhage (IVH) in preterm infants predisposed to neonatal brain damage.

\section{Materials and Methods}

132 extremely preterm infants born with a gestational age between $230 / 7$ and $276 / 7$ weeks, treated at the perinatal intensive care center of the University of Bonn between January 1, 1999 and August 31, 2004 were included in this retrospective clinical cohort study. 174 infants were eligible for the study. 42 infants were excluded because in these infants no coagulation tests were performed. The excluded infants were born with a higher gestational age and had lower Clinical Risk Index for Babies (CRIB) Scores and lower IL-6 levels indicating that these infants were healthier than the included infants.

The study population was grouped according to the occurrence of IVH. In addition, the infants were divided into groups with serum IL-6 $>/<100 \mathrm{pg} / \mathrm{ml}$, respectively, for the analysis of the coagulation parameters.

By reviewing hospital records of the patients and maternal birth protocols we collected relevant clinical data including day and time of birth, clinical diagnosis of chorioamnionitis (maternal temperature $>38^{\circ} \mathrm{C}, \mathrm{CRP}>2 \mathrm{mg} / \mathrm{dl}$, leukocytosis $>15,000 / \mu \mathrm{l}$ ), gender, gestational age, Apgar score at $5 \mathrm{~min}$, catecholamine treatment (dopamine, dobutamine, epinephrine) within the first $72 \mathrm{~h}$ postnatal age to maintain arterial blood pressure above the 10th percentile according to Watkins et al. [14], severity of respiratory distress syndrome (RDS), development of pneumothorax, and birth weight. All clinical data were anonymised prior to analysis. Gestational age at delivery was determined by first trimester ultrasound examination.

The diagnosis of intraventricular hemorrhage was made on serial ultrasound examinations $(8.5-10 \mathrm{MHz}$ transducer, Vingmed Vivid FiVe) on days 1, 3 and 7 postnatal age. The maximal degree of IVH was confirmed by cranial ultrasound at day 7 postnatal age.

The techniques for obtaining and handling blood samples and measuring the coagulation parameters have been described in detail previously [11]. In brief, coagulation tests were performed as part of routine laboratory testing within the first hour of life prior to vitamin $\mathrm{K}$ administration ( $0.2 \mathrm{mg}$ phytomenadione solution intravenous). The measured components of the coagulation system included activities of clottable fibrinogen, coagulation factors II, V, VII, VIII and X, as well as antithrombin. Full blood cell count, IL- 6 and C-reactive protein were assessed as part of the routine blood sampling within the first hour of life. The IL- 6 assay (Immulite, DPC-Biermann, Bad Nauheim, Germany) sensitivity was $2 \mathrm{pg} / \mathrm{ml}$, the averaged intra- and interassay variation coefficients were 5.1 and $6.5 \%$, respectively.

Perinatal factors that may interfere with the development of IVH (clinical chorioamnionitis, small for gestational age: defined by birth weight $<3$ rd percentile, Apgar score at $5 \mathrm{~min}$, severity of respiratory distress syndrome, incidence of pneumothorax, catecholamine treatment within the first $72 \mathrm{~h}$ of life) were evaluated.

According to the clinical protocol, arterial hypotension was defined as mean arterial blood pressure $(\mathrm{BP})<10$ th percentile for weight and postnatal age [14]. The upper and lower limits of the mean arterial blood pressure levels (MABP) were adapted to postnatal age according to the references for normal postnatal cardiocirculatory adaptation.

The treatment of arterial hypotension followed a standardized protocol. Treatment started with up to $2 \times 10 \mathrm{ml} / \mathrm{kg}$ saline infusions over $30 \mathrm{~min}$ each, followed by catecholamine treatment (dopamine infusion 5-10 $\mu \mathrm{g} / \mathrm{kg} / \mathrm{min}$, dobutamine infusion 5-10 $\mu \mathrm{g} /$ $\mathrm{kg} / \mathrm{min}$ or epinephrine infusion $0.1-0.3 \mu \mathrm{g} / \mathrm{kg} / \mathrm{min}$ ) to maintain $\mathrm{BP}$ between the 10th and 50th percentiles.

The CRIB score was evaluated in order to assess the severity of illness in the first $12 \mathrm{~h}$ of life. The validity of the CRIB score in predicting neonatal morbidity and mortality from the severity of clinical conditions in the first $12 \mathrm{~h}$ of life has been demonstrated in extremely preterm infants $[15,16]$. The CRIB score was determined for all infants taking birth weight, gestational age, presence 
or absence of congenital malformations, worst base excess, minimum and maximum appropriate fractions of inspired oxygen into account.

\section{Data Analysis}

Values between two groups of patients were compared using Mann-Whitney U test and $\chi^{2}$ test with two-sided $p$ values. $p<0.05$ was considered as statistically relevant. A contingency table was applied to analyze the relation between two or more categorical variables including the linear-by-linear correlation test. Multivariable logistic regression analysis was performed to identify independent risk factors for the development of IVH. Data were analyzed using statistical software SPSS 14.0 (SPSS Inc., Chicago, Ill., USA).

Table 1. Demographic data of the study population $(\mathrm{n}=132)$

\begin{tabular}{ll}
\hline Male/female, $\mathrm{n}$ & $65 / 67$ \\
Gestational age, weeks+days & $25+5(23+0$ to $27+6)$ \\
Birth weight, $\mathrm{g}$ & $683(333-1,282)$ \\
IVH yes/no, $\mathrm{n}(\%)$ & $58(43 \%) / 74(56 \%)$ \\
IVH grade $1 / 2 / 3 / 4, \mathrm{n}$ & $11 / 10 / 15 / 22$ \\
Week of gestation $(23 / 24 / 25 / 26 / 27), \mathrm{n}$ & $26 / 24 / 22 / 37 / 23$
\end{tabular}

Gestational age and birth weight are given as median and range.
Ethics

The study protocol was approved by the Ethics Committee of the Medical Faculty of the University of Bonn (048/08).

\section{Results}

General demographic data of the study population are presented in table 1.58 of the 132 infants (43\%) developed IVH.

Table 2 summarizes the neonatal data of the study population divided into groups according to the occurrence of $\mathrm{IVH}$ as defined by cranial ultrasound examination on day 7 postnatal age. Both groups were similar with respect to gender. Infants who developed an IVH were born at significantly lower gestational age compared to those without IVH. They also had significantly higher CRIB scores and IL-6 levels than infants without IVH, whereas hematocrit was significantly lower. Antenatal steroid treatment, birth weight, small for gestational age status, serum CRP concentration and platelet count did not differ between the two groups. In the IVH group, we found significantly more infants with air leak syndromes and severe RDS.

Table 2. Demographic data and routine laboratory at the first day of life according to the diagnosis of IVH confirmed by ultrasound at the 7 th day of life (median and range)

\begin{tabular}{|c|c|c|c|}
\hline & IVH yes $(\mathrm{n}=58)$ & IVH no $(\mathrm{n}=74)$ & $\mathrm{p}$ \\
\hline Male/female, $\mathrm{n}$ & $29 / 29$ & $37 / 37$ & n.s. \\
\hline GA, weeks+days & $25+0(23+1$ to $27+6)$ & $26+0(23+0$ to $27+6)$ & 0.01 \\
\hline Antenatal steroids, n (\%) & $48(84)$ & $67(93)$ & n.s. \\
\hline Chorioamnionitis, n (\%) & $30(52)$ & $22(30)$ & 0.01 \\
\hline Birth weight, $g$ & $654(333-960)$ & $712(350-1,282)$ & n.s. \\
\hline SGA, n (\%) & $4(7)$ & $11(15)$ & n.s. \\
\hline APGAR score at $5 \mathrm{~min}$ & $8(3-10)$ & $8(1-10)$ & n.s. \\
\hline CRIB score & $9(1-20)$ & $8(1-19)$ & 0.002 \\
\hline IL-6, pg/ml & $97(4-38,800)$ & $26(5-7,000)$ & 0.005 \\
\hline $\mathrm{CRP}, \mathrm{mg} / \mathrm{dl}$ & $0.4(0.2-17.1)$ & $0.2(0-48.7)$ & n.s. \\
\hline Hct, $\%$ & $41(12-69)$ & $44(26-56)$ & 0.006 \\
\hline Platelets, $10^{9} / 1$ & $179(35-290)$ & $197(54-338)$ & n.s. \\
\hline RDS grades $0 / 1 / 2 / 3 / 4, \mathrm{n}$ & $3 / 2 / 8 / 23 / 22$ & $9 / 8 / 13 / 24 / 16$ & 0.008 \\
\hline Air leak, n (\%) & $13(22)$ & $6(8)$ & 0.02 \\
\hline Catecholamine treatment, $\mathrm{n}(\%)$ & $52(91)$ & $54(73)$ & 0.01 \\
\hline
\end{tabular}

Antenatal steroids $(\mathrm{n}=129)$ : maternal betamethasone treatment $2 \times 12 \mathrm{mg}$ (i.v.) $>24$ h prior to delivery; chorioamnionitis $(\mathrm{n}=132)$ : clinical diagnosis of chorioamnitis (maternal temperature $>38^{\circ} \mathrm{C}$, leukocytosis $>15,0000 / \mu \mathrm{l}$, CRP $>2 \mathrm{mg} / \mathrm{dl}$ ); SGA ( $=$ $132)$ : birth weight $<3$ rd percentile; RDS: maximal grade on chest X-ray; air leak $(n=132)$ : development of pneumothorax $<72 \mathrm{~h}$ postnatal age; catecholamine treatment $(n=130)$ : any catecholamine treatment (dopamine, dobutamine, epinephrine) to maintain blood pressure $>10$ th percentile $<72 \mathrm{~h}$ postnatal age [13]. All blood tests were taken at routine blood sampling within the first hour of life. $\mathrm{GA}=$ Gestational age. 
Table 3. Activities of clotting factors, fibrinogen and antithrombin on the first day of life before administration of vitamin $\mathrm{K}$ according to the diagnosis of IVH confirmed by ultrasound at the 7th day of life (median and range)

\begin{tabular}{lcll}
\hline & $\begin{array}{l}\text { IVH yes } \\
(\mathrm{n}=58)\end{array}$ & $\begin{array}{l}\text { IVH no } \\
(\mathrm{n}=74)\end{array}$ & $\mathrm{p}$ \\
\hline Fibrinogen, mg/dl & $109(1-526)$ & $125(20-547)$ & $\mathrm{n} . \mathrm{s.}$ \\
Factor II, \% & $23(10-52)$ & $32(13-62)$ & 0.001 \\
Factor V, \% & $48(3-132)$ & $67(14-171)$ & 0.001 \\
Factor VII, \% & $23(4-76)$ & $31(6-69)$ & 0.001 \\
Factor VIII, \% & $81(20-195)$ & $90(13-174)$ & n.s. \\
Factor X, \% & $31(10-68)$ & $40(16-102)$ & 0.003 \\
Antithrombin, \% & $24(3-54)$ & $29(9-53)$ & 0.003 \\
\hline
\end{tabular}

The results of the coagulation tests are shown in table 3. The vitamin K-dependent factors II, VII and X, and factor $\mathrm{V}$ as well as antithrombin were significantly lower in infants with IVH than in those without IVH. Factor VIII did not differ between the two groups.

A stepwise multivariable logistic regression analysis revealed an independent association of low factor VII activity (OR 1.06, CI 1.02-1.09, $\mathrm{p}=0.001$ ), low hematocrit (OR 1.07, CI 1.009-1.137, $\mathrm{p}=0.024)$ and incidence of air leak (OR 4.26, CI 1.18-15.4, $\mathrm{p}=0.027$ ) with the development of IVH. ORs with 95\% CIs were calculated after adjustment for gestational age, chorioamnionitis, CRIB score, hematocrit, serum IL-6, severity of RDS, incidence of air leak, coagulation factor VII, and antithrombin.

When the coagulation parameters were examined according to the diagnosis of increased serum concentration of IL-6 (>100 pg/ml) (table 4), factor VII was significantly lower in the group with increased IL-6. In contrast, fibrinogen was significantly higher in the group with increased IL-6. Activities of the other clotting factors and antithrombin did not differ between both groups.

\section{Discussion}

The risk of systemic fetal inflammation and chorioamnionitis is inversely related to gestational age $[17,18]$. We present a retrospective clinical study analyzing serum IL-6, coagulation profile and development of IVH in a cohort of preterm infants born with $230 / 7$ to $276 / 7$ weeks of gestational age. Thereby, we intended to focus on the pathophysiology of the development of IVH in infants at highest risk of cerebral morbidity. The results of our
Table 4. Incidence of IVH and activities of clotting factors, fibrinogen and of antithrombin in the study population on the first day of life according to the diagnosis of elevated IL-6 serum concentration $>100 \mathrm{pg} / \mathrm{ml}$ (median and range)

\begin{tabular}{lcll}
\hline & $\begin{array}{l}\text { IL-6 }>100 \mathrm{pg} / \mathrm{ml} \\
(\mathrm{n}=48)\end{array}$ & $\begin{array}{l}\mathrm{IL}-6<100 \mathrm{pg} / \mathrm{ml} \\
(\mathrm{n}=80)\end{array}$ & $\begin{array}{l}\mathrm{p} \\
\text { value }\end{array}$ \\
\hline IVH, n (\%) & $29(60)$ & $29(36)$ & 0.01 \\
Fibrinogen, mg/dl & $147(20-547)$ & $96(1-382)$ & 0.006 \\
Factor II, \% & $26(10-55)$ & $28(12-62)$ & n.s. \\
Factor V, \% & $60(14-132)$ & $60(3-171)$ & n.s. \\
Factor VII, \% & $24(5-76)$ & $30(4-69)$ & 0.034 \\
Factor VIII, \% & $94(37-195)$ & $78(13-174)$ & n.s. \\
Factor X, \% & $34(10-102)$ & $35(17-83)$ & n.s. \\
Antithrombin, \% & $25(3-54)$ & $28(8-53)$ & n.s. \\
\hline
\end{tabular}

study emphasize that activation of proinflammatory cytokines (IL-6) is associated with decreased vitamin K-dependent coagulation factors and, subsequently, the development of IVH.

Several studies on preterm infants demonstrated an association of histopathologically confirmed chorioamnionitis and funisitis with the development of IVH [1721]. Vergani et al. [19] even reported a dose-dependent relationship between severity of acute placental inflammatory lesions and the severity of IVH.

Early sepsis is associated with an increased risk of IVH [22]. IL-6 is a suitable marker to early detect neonatal sepsis as serum levels reach a peak 3-4 h after endotoxin stimulation $[23,24]$. Consistent with previously published data [4], we found an association of raised serum IL-6 with the development of IVH in extremely premature infants. Possible pathophysiological mechanisms include systemic and local hemodynamic changes as well as cerebral endothelial damage of the germinal matrix and the white matter as a consequence of inflammation $[1,4]$. In previous studies, IL- 6 levels were also examined in maternal serum and in cord blood. Sorokin et al. [6] analyzed the serum concentration of IL- 6 in 475 women between 23 and 32 weeks of gestation at risk for preterm birth who were not in labor and had intact membranes. They reported an association of elevated maternal serum IL- 6 with IVH. In umbilical cord blood increased levels of proinflammatory cytokines were not consistently associated with the development of IVH in previous studies [25]. In a cohort of 69 very low birth weight infants, Kassal et al. [5] found elevated umbilical vein IL-6 levels in infants who subsequently developed IVH. In contrast, Bhandari et al. [26] did not observe an association of cord 
blood IL-6 levels and IVH in 116 preterm infants with a gestational age of 23-34 weeks.

Consequently, prepartal antibiotic treatment of the mothers might represent an approach to reduce the incidence of IVH. A meta-analysis comprising seven trials and a total of 657 patients showed a significantly reduced risk of neonatal sepsis by $68 \%$ and of IVH by $50 \%$ in mothers with premature rupture of the membranes who had received antenatal antibiotic treatment [27].

There is growing evidence that alterations of the coagulation system are associated with the occurrence of IVH. In our study, based on the assessment of the coagulation profile shortly after birth, multiple regression analysis identified diminished activity of factor VII as independent significant risk factor for the development of IVH.

Similar observations have been made by Piotrowski et al. [28]. In a relatively small cohort of 38 extremely low birth weight infants, they reported a severe derangement of the coagulation system with significantly lower plasma factor VII levels at the first day of life in infants with IVH grade III/IV compared to infants with IVH grade I/II. A prospective study on 50 infants born with a gestational age less than 33 weeks showed a significant association of hypocoagulability in the first $4 \mathrm{~h}$ of life with subsequent onset or progression of IVH. In addition, the authors reported higher rates of hypocoagulopathy and IVH in babies born to mothers with premature rupture of the membranes and suspected amnionitis [29].

Recombinant activated factor VII (rFVIIa) has been proposed as prophylaxis of IVH. In a phase 1 study, Veldman et al. [30] treated 10 extremely preterm infants with $100 \mu \mathrm{g} / \mathrm{kg} \mathrm{rFVIIa}$ every $4 \mathrm{~h}$ within the first $72 \mathrm{~h}$ of life. $20 \%$ of the neonates developed grade III or IV IVH, which is similar to the IVH rate in untreated patients. However, the study did not provide a sufficient sample size to assess minor effects of rFVIIa on IVH.

$\mathrm{Xu}$ et al. [31] investigated the effect of genetically imposed severe factor VII deficiency on lipopolysaccharide (LPS)-induced lethal endotoxinemia in a mouse model. After administration of a lethal dose of LPS, partial deficient factor VII mice presented with reduced mortality, coagulation activity, and inflammatory responses compared to similarly treated wild-type mice. These results indicate that factor VII deficiency may be protective in acute inflammatory states by down regulating both the inflammatory response and the tissue factor-/factor VII-induced coagulation cascade. Though, mice with a total factor VII deficiency do not survive the neonatal period [31].

Further research is required to analyze the impact of factor VII on the interaction of inflammation and coagu- lation, and to estimate risks and benefits of administered rFVIIa in infants at high risk of developing IVH.

Elevated fibrinogen levels were also found to associate with increased IL- 6 in our cohort. This seems likely to be related to the fact that fibrinogen belongs to the group of acute-phase proteins.

Recent studies give evidence that genetic factors also influence the individual risk of perinatal brain injury. It is noteworthy that many of these studies focused on genes related to coagulation and inflammation $[32,33]$.

We determined the CRIB score as predictor for neonatal morbidity and mortality in order to assess the severity of clinical conditions in the first $12 \mathrm{~h}$ of life. We found a linear correlation between increased CRIB score and risk of development of IVH.

Fluctuation of systemic blood flow and impaired cerebral venous return are known to affect cerebral perfusion leading to IVH in extremely preterm infants [34]. In our study, the need to extend circulatory support from volume to catecholamine treatment was significantly associated with the development of IVH. In addition, development of pneumothorax leading to impaired venous return from the brain was found to be an independent risk factor for IVH in our cohort. We are aware of the limitations of these findings due to the retrospective study design. Prospective evaluation of cardiac function, venous return by measuring superior vena cava flow and hemodynamic relevance of patent ductus arteriosus shunt will help to elucidate the impact of altered blood circulation on the development of IVH [35].

Consistent with previous studies low hematocrit at the first day of life indicative for low intravascular volume was related to the incidence of IVH. Delayed cord clamping in preterm infants results in a higher initial hematocrit and a lower incidence of IVH. This observation supports the hypothesis that low hematocrit represents an independent risk factor for the development of IVH $[36,37]$.

\section{Conclusion}

The results of our study extend the knowledge on the complex pathophysiology of development of IVH in extremely preterm infants. The study confirms previous findings that - irrespectively of the infants' immaturity - elevated serum IL- 6 concentrations are associated with alterations of the coagulation profile at the first day of life and the development of IVH. Decreased activity of factor VII and low hematocrit shortly after birth are independent risk factors for the development of IVH. 


\section{References}

1 McCrea HJ, Ment LR: The diagnosis, management, and postnatal prevention of intraventricular hemorrhage in the preterm neonate. Clin Perinatol 2008;35:777-792.

$\checkmark 2$ Vohr BR, Allan WC, Westerveld M, Schneider KC, Katz KH, Makuch RW: School-age outcomes of very low birth weight infants in the indomethacin intraventricular hemorrhage prevention trial. Pediatrics 2003;111:e340-e346.

>3 Mercier CE, Dunn MS, Ferrelli KR, Howard DB, Soll RF, Vermont Oxford Network ELBW Infant Follow-Up Study Group: Neurodevelopmental outcome of extremely low birth weight infants from the Vermont Oxford network: 1998-2003. Neonatology 2010; 97:329-338.

$\checkmark 4$ Heep A, Behrendt D, Nitsch P, Fimmers R, Bartmann P, Dembinski J: Increased serum levels of interleukin 6 are associated with severe intraventricular haemorrhage in extremely premature infants. Arch Dis Child Fetal Neonatal Ed 2003;88:F501-F504.

5 Kassal R, Anwar M, Kashlan F, Simulian J, Hiatt M, Hegyi T: Umbilical vein interleukin-6 levels in very low birth weight infants developing intraventricular hemorrhage. Brain Dev 2005;27:483-487.

-6 Sorokin Y, Romero R, Mele L, Wapner RJ, Iams JD, Dudley DJ, et al: Maternal serum interleukin-6, C-reactive protein, and matrix metalloproteinase- 9 concentrations as risk factors for preterm birth $<32$ weeks and adverse neonatal outcomes. Am J Perinatol 2010;27:631-640.

$\checkmark 7$ Hassan HJ, Leonardi A, Chelucci C, Mattia G, Macioce G, Guerriero R, et al: Coagulation factors in human embryonic-fetal development: preferential expression of the FVII/ tissue factor pathway. Blood 1990;76:11581164.

-8 Andrew M, Paes B, Milner R, Johnston M, Mitchell L: Development of the human coagualtion system in the healthy premature infant. Blood 1988;72:1651-1657.

$\checkmark 9$ Andrew M, Paes B, Milner R, Johnston M, Mitchell L: Development of the human coagualtion system in the full-term infant. Blood 1987;70:165-172.

-10 Reverdiau-Moalic P, Delahousse B, Body G Bardos P, Leroy J, Gruel Y: Evolution of blood coagulation activators and inhibitors on the healthy human fetus. Blood 1996;88:900906.

11 Poralla C, Traut C, Hertfelder HJ, Oldenburg J, Bartmann P, Heep A: The coagulation system of extremely preterm infants: influence of perinatal risk factors on coagulation. J Perinatol 2011 [Epub ahead of print].

-12 Levi M, Keller TT, van Gorp E, ten Cate H: Infection and inflammation and the coagulation system. Cardiovasc Res 2003;60:2639.

$\checkmark 13$ van der Poll T, de Jonge E, Levi M: Regulatory role of cytokines in disseminated intra- vascular coagulation. Semin Thromb $\mathrm{He}$ most 2001;27:639-651.

14 Watkins AM, West CR, Cooke RW: Blood pressure and cerebral haemorrhage and ischaemia in very low birthweight infants. Early Hum Dev 1989;19:103-110.

15 Bührer C, Grimmer I, Metze B, Obladen M: The Crib (Clinical Risk Index for Babies) score and neurodevelopmental impairment at one year corrected age in very low birth weight infants. Intens Care Med 2000;26: 325-329.

16 Lago P, Freato F, Bettiol T, Chiandetti L, Vianello A, Zaramella P: Is the CRIB score (Clinical Risk Index for Babies) a valid tool in predicting neurodevelopmental outcome in extremely low birth weight infants? Biol Neonate 1999;76:220-227.

17 Alexander JM, Gilstrap LC, Cox SM, McIntire DM, Leveno KJ: Clinical chorioamnionitis and the prognosis for very low birth weight infants. Obstet Gynecol 1998;91:725729.

18 Morales WJ, Washington SR III, Lazar AJ: The effect of chorioamnionitis on perinatal outcome in preterm gestation. J Perinatol 1987;7:105-110.

19 Vergani P, Patanè L, Doria P, Borroni C, Cappellini A, Pezzullo JC, Ghidini A: Risk factors for neonatal intraventricular haemorrhage in spontaneous prematurity at 32 weeks gestation or less. Placenta 2000;21: 402-407.

-20 Moscuzza F, Belcari F, Nardini V, Bartoli A, Domenici C, Cuttano A et al: Correlation between placental histopathology and fetal/ neonatal outcome: chorioamnionitis and funisitis are associated to intraventricular haemorrage and retinopathy of prematurity in preterm newborns. Gynecol Endocrinol 2011;27:319-323.

21 Furukawa S, Sameshima H, Ikenoue T: Circulatory disturbances during the first postnatal $24 \mathrm{~h}$ in extremely premature infants 25 weeks or less of gestation with histological fetal inflammation. J Obstet Gynaecol Res 2008;34:27-33.

22 Linder $\mathrm{N}$, Haskin O, Levit O, Klinger G, Prince T, Naor N, et al: Risk factors for intraventricular hemorrhage in very low birth weight premature infants: a retrospective case-control study. Pediatrics 2003 111:e590-e595.

-23 Krueger M, Nauck MS; Sang S, Hentschel R, Wieland H, Berner R: Cord blood levels of interleukin- 6 and interleukin- 8 for the immediate diagnosis of early-onset infection in premature infants. Biol Neonate 2001;80: 118-123.

24 Koch L, Fritzsching B, Frommhold D, Poeschl J: Lipopolysaccharide-induced expression of Th1/Th2 cytokines in whole neonatal cord and adult blood: role of nuclear factorkappa B and p38 MAPK. Neonatology 2011; 99:140-145.
25 Thomas W, Speer CP: Chorioamnionitis: important risk factor or innocent bystander for neonatal outcome? Neonatology 2011;99: 177-187.

26 Bhandari V, Buhimschi CS, Han CS, Lee SY, Pettker CM, Campbell KH, et al: Cord blood erythropoietin and interleukin- 6 for prediction of intraventricular hemorrhage in the preterm neonate. J Matern Fetal Neonatal Med 2011;24:673-679.

27 Egarter C, Leitich H, Husslein P, Kaider A, Schemper M: Antibiotic treatment in preterm premature rupture of membranes and neonatal morbidity: a metaanalysis. Obstet Gynecol 1996;88:303-309.

28 Piotrowski A, Dabrowska-Wojciak I, Mikinka M, Fendler W, Walas W, Sobala W, et al: Coagulation abnormalities and severe intraventricular hemorrhage in extremely low birth weight infants. J Matern Fetal Neonatal Med 2010;23:601-606.

29 McDonald MM, Johnson ML, Rumack CM, Koops BL, Guggenheim MA, Babb C, et al: Role of coagulopathy in newborn intracranial hemorrhage. Pediatrics 1984;74:26-31.

30 Veldman A, Josef J, Fischer D, Volk WR: A prospective pilot study of prophylactic treatment of preterm neonates with recombinant activated factor VII during the first 72 h of life. Pediatr Crit Care Med 2006;7: 34-39.

-31 Xu H, Ploplis VA, Castellino FJ: A coagulation factor VII deficiency protects against acute inflammatory in mice. J Pathol 2006; 210:488-496.

32 Baier RJ: Genetics of perinatal brain injury in the preterm infant. Front Biosci 2006;11: 1371-1387.

33 Ryckman KK, Dagle JM, Kelsey K, Momany AM, Murray JC: Replication of genetic associations in the inflammation, complement, and coagulation pathways with intraventricular hemorrhage in LBW preterm neonates. Pediatr Res 2011;70:90-95.

34 Tsuji M, Saul JP, du Plessis A, et al: Cerebral intravascular oxygenation correlates with mean arterial pressure in critically ill premature infants. Pediatrics 2000;106:625632

-35 Osborn DA, Evans N, Kluckow M: Hemodynamic and antecedent risk factors of early and late periventricular/intraventricular haemorrhage in premature infants. Pediatrics 2003;112:33-39.

36 Kakkilaya V, Pramanik AK, Ibrahim H, Hussein S: Effect of placental transfusion on the blood volume and clinical outcome of infants born by caesarean section. Clin Perinatol 2008;35:561-570.

>37 Mercer JS, Vohr BR, McGrath MM, Padbury JF, Wallach M, Oh W: Delayed cord clamping in very preterm infants reduces the incidence of intraventricular hemorrhage and late-onset sepsis: a randomized, controlled trial. Pediatrics 2006;117:1235-1242. 